\title{
ALGUNAS CONSIDERACIONES CON RESPECTO A LAS ACCIONES CON DERECHO A VETO
}

\author{
SOME CONSIDERATIONS ON \\ THE ACTIONS WITH RIGHT TO VETO
}

\section{Arturo Ronald Cardenas Krenz}

\section{RESUMEN}

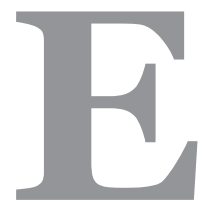

l artículo trata sobre las denominadas acciones con derecho a veto, un tipo especial de acciones poco difundidas, pero que pueden ser de gran utilidad. Se estudiará su historia, ventajas y desventajas a partir de la revisión de la legislación peruana sobre la materia.

Palabras clave: acciones, clase de acciones, acciones con derecho a veto.

\begin{abstract}
The article studies the so-called actions with the right of veto, a special type of actions that are not very widespread, but which can be very useful. Its history, advantages and disadvantages are analyzed from the revision of the Peruvian legislation on the matter.
\end{abstract}

Keywords: Actions. types of actions, actions with the right to veto. 


\section{INTRODUCCIÓN}

Las acciones con derecho a veto constituyen, sin duda, un tipo de acciones muy particular e interesante, ${ }^{1}$ tanto por su relevancia conceptual como por la trascendencia que pueden tener en la gestión de la sociedad; sobre dicho tema, trata el presente artículo, analizando la materia a partir de la experiencia peruana.

A fin de comprender su naturaleza y legalidad, es necesario revisar, en primer término, el concepto de acción, para pasar luego a revisar el origen histórico en nuestro medio de este tipo especial de acciones.

De acuerdo con Escuti (2006, p. 199), podemos decir que, conceptualmente, "la acción es la división alícuota de la cifra estatutaria del capital social". Por otro lado, desde una perspectiva más integral, señala Bote García (2013, p. 150), que la acción puede ser definida "como el título que representando una parte alícuota del capital social confiere a su titular legítimo la condición de socio", presentando de esta manera un triple aspecto: como parte del capital, como derecho y como título valor.

En el Perú, Elías Laroza (1999, p. 193), siguiendo la línea doctrinaria que apunta al triple alcance conceptual del término, se refiere a "la acción como parte alícuota del capital social, representativa de una porción del mismo; la acción como vehículo para adquirir la condición de socio y ser, en consecuencia, titular de un conjunto especial de derechos y obligaciones; y, finalmente, la acción como título".

A su turno, para Hundskopf (2011, p. 144), las acciones representan partes alícuotas del capital social, expresan el status de socio y constituyen a la vez un título-valor, siendo, como bienes muebles, representativas de los derechos del accionista.

$\mathrm{Al}$ representar dicho capital, el beneficio que otorgan por excelencia las acciones es el de otorgamiento de dividendos. Naturalmente que otro derecho que otorgan -típico de las mismas-, es que facultan a intervenir y votar en las juntas generales, ya sea generales o especiales, pudiendo generar o no, el derecho a voto, tal como lo señala el artículo 98 de la Ley General de Sociedades peruana.

Así como la ley ha dejado a la voluntad de los fundadores cuestiones como fijar el valor nominal de las acciones, o el capital mínimo para constituir la sociedad, del mismo modo parece lógico que, al amparo del principio de la autonomía de la voluntad, puedan crearse acciones de carácter especial. No hay ninguna obligación legal de establecer esta clase de acciones, como tampoco ningún impedimento, por lo que hacerlo constituye una genuina manifestación de la autonomía de la voluntad de las partes.

Sin perjuicio de ello, podemos por supuesto encontrarnos con ciertos límites, algunos derivados de la naturaleza de la institución, otros de la ley, y algunos derivados de la voluntad

\footnotetext{
${ }^{1}$ De hecho, como señala Molano, una de las relaciones más intensas e interesantes en el ámbito de las sociedades cerradas es la que puede darse entre el socio mayoritario y el socio minoritario, lo que es más relevante en culturas empresariales en donde el volumen del mercado de capitales no es tan alto como el de países anglosajones y suele darse el caso de sociedades con un accionista mayoritario que controla la empresa, lo que implica el riesgo de desconocer el derecho de las minorías (Molano, 2011, p. 1).
} 
estatutaria, entre otros. Así, la LGS, en su artículo 88, establece la posibilidad de que en una sociedad anónima existan diversos tipos de acciones en función de los derechos que otorguen a sus titulares y/o por las obligaciones que generen, mas siempre teniendo en cuenta que todas las acciones de un mismo tipo otorgarán los mismos derechos y/u obligaciones, de acuerdo al artículo 86 de la misma ley, y que el valor nominal no puede ser un criterio de distinción.

Como bien señala Echaiz (2009, p. 400), la sociedad, como institución típica del Derecho Mercantil, no es ajena al ardoroso debate sobre su naturaleza jurídica. Empero, quizás más importante que tratar de encasillarla en una sola categoría, sería comprender su naturaleza dinámica, su resiliencia ante los tiempos y necesidades sociales como un rasgo más bien positivo, que ha permitido su perduración a través del tiempo, manteniendo su dinámica existencia.

\section{LAS ACCIONES CON DERECHO A VETO}

Dada la posibilidad de generar diversos tipos de acciones, corresponde analizar si las denominadas "acciones con derecho a veto" pueden incluirse en dicha categoría.

Es de advertir que, al hablar de los tipos de acciones, autores como Bote García, Escuti o Beaumont Callirgos, no hacen referencia a ellas. ${ }^{2}$ Tampoco lo hace de manera expresa la Ley General de Sociedades peruana.

Para poder entender la posibilidad del derecho a veto, pareciera conveniente incidir en su consideración como una especie de derechos personales corporativos, teniendo en cuenta que estas acciones no tienen un mero carácter económico, sino que tienen que ver con la propia gestión de la empresa. $\mathrm{O}$, en todo caso, aunque el término no es común en nuestro medio, podría hablarse de derechos parapolíticos (como, por ejemplo, cuando se establece el derecho elegir a determinados directores, tal como lo establece la legislación argentina al amparo del artículo 207 de su Ley de Sociedades) (Roitman, Aguirre y Chiavassa, 2010, p. 709).

Las acciones con derecho a veto, como tipo especial de acciones, son llamadas también "acciones doradas" o "Golden shares", otorgando a su titular el derecho a vetar un acuerdo, de modo que sin su aprobación no podría adoptarse este. Mediante ellas, por tanto, se busca dejar sin efecto o impedir que la Junta General de Accionistas adopte acuerdos sin contar con la anuencia o conformidad de los titulares de estas acciones, quienes suelen ser una minoría.

Un dato curioso de estas acciones es que, no obstante que estamos hablando de una figura típicamente societaria, correspondiente a un ámbito eminentemente privado, ellas

\footnotetext{
${ }^{2}$ Beaumont menciona las siguientes clases: Acciones ordinarias o comunes y acciones preferenciales; acciones de fundador y acciones ordinarias; acciones reembolsables; acciones con derecho a voto y acciones privilegiadas sin derecho a voto; acciones afectas a obligaciones adicionales; y acciones con derecho exclusivo a suscripción de nuevas acciones. Sin embargo, señala que estas clases de acciones pueden enumerarse entre otras.
} 
nacieron en el Perú país allá por los años 70, como mecanismo de defensa de los intereses del Estado. ${ }^{3}$

De esta manera, su objeto era evitar que se adopten acuerdos sin la anuencia o conformidad del Estado en las sociedades de economía mixta, en los casos en que éste tuviere una participación minoritaria, invocándose por cierto el interés público. La regulación de dicha figura tuvo que hacerse con cierta prudencia pues, de ser una facultad irrestricta, originaría una situación de desequilibrio entre los socios, lo cual desalentaría la constitución de sociedades de economía mixta en donde participen en armonía el interés público y el interés privado; de allí que se restringiera a ciertos casos específicos la constitución de este tipo de acciones, como cuando pudiera ponerse en peligro la estabilidad de la sociedad. ${ }^{4}$

Un hito importante en su desarrollo será la dación de la Ley 26844, del 16 de julio de 1997, que apareció bajo el epígrafe "Establecen disposiciones aplicables al proceso de promoción de la inversión privada en las empresas del Estado del Sector Hidrocarburos”, a partir de la cual se regula este tipo de acciones en forma expresa definiendo su régimen, siendo desde aquel entonces en que se les empieza a llamar "acciones doradas", "acciones de oro" o "Golden shares".

Posteriormente, la Ley 26876, del 18 de noviembre de 1997, Ley Antimonopolio y Antioligopolio del Sector Eléctrico, amplió los alcances de la Ley 26844 para incluir a las empresas de energía eléctrica dedicadas a la generación, transmisión o distribución de energía.

De esta manera, las acciones con derecho a veto en el Perú (existentes también en otros países con objetivos variados) fueron desarrollándose como un medio para que el Estado participe en determinados servicios públicos considerados estratégicos, conforme a los conceptos de la época.

Otro hito importante -como ha resaltado también Hundskopf (2011) - será la expedición del Decreto Supremo No. 061-2002-EF que facilitó la transferencia de las acciones especiales de propiedad del Estado, creadas por la Ley 26844, de las empresas dedicadas a la generación, transmisión o distribución de energía eléctrica que sean parte del proceso de promoción de la inversión privada, cuando así lo decida la COPRI. Es de mencionar, además que, siendo conveniente para la competitividad del país en concursos públicos internacionales, se autorizó, mediante el mismo Decreto, la transferencia de acciones de la clase especial mencionada.

Finalmente, otro momento relevante, sería la promulgación del Decreto Legislativo No. 1031, del 23 de junio de 2008, dado para promover la eficiencia de la actividad empresarial del Estado, en donde se ratifica - a tono con los tiempos- que dicha actividad empresarial se desarrolla solo en forma subsidiaria y por razones de alto interés público o manifiesta conveniencia nacional, sin que ello signifique una reserva exclusiva a favor del Estado o se impida el acceso de la inversión privada, como destaca Hundskopf (2011, p. 162).

Es de observar, por tanto, que el desarrollo de las acciones sin derecho a veto fue orientando su aprovechamiento a procesos de privatización, como una clase especial de acciones, las

\footnotetext{
${ }^{3}$ Para una visión más detallada de cómo existen forma diversas mediante las cuales el Estado interviene sobre todo en el sector de las sociedades por acciones, especialmente respecto a las grandes empresas, véase Brunetti (2002, pp. 39 y 40).

${ }^{4}$ Para más detalle sobre este particular, véase: Hundskopf (2011, p. 155).
} 
cuales pueden clasificarse dentro de la categoría de acciones privilegiadas, siguiendo -como dice Hundskopf (2011, p. 164) - un esquema de funcionamiento traído del derecho societario europeo, específicamente del Reino Unido, constituyendo "una técnica de privatización utilizada en aquellos supuestos en que se estimó necesario compatibilizar una operación de transferencia de una empresa pública a la esfera privada, con la debida protección de los intereses nacionales".

Naturalmente que, así como se ha aplicado ya en procesos de privatización, nada impide que con la actual legislación se siga aplicando en otros procesos del mismo tipo.

En cuanto a su naturaleza jurídica, como menciona el mismo autor, en la doctrina societaria se señala que los derechos del accionista son una tercera categoría de derechos, siendo una especie de derechos personales corporativos, diferente de los derechos reales o de los derechos de crédito (Hundskopf, 2012, p. 119).

En tal sentido, las acciones con derecho a veto estarían, en principio, dentro del tercer tipo de derechos mencionados; sin embargo, consideramos que, por sus propias características, estaríamos más bien ante una categoría distinta, teniendo en cuenta que -históricamente hablando- ellas han representado no solo un interés personal o corporativo, sino más bien de carácter estatal. No obstante ello, es muy probable que, por las razones que señalamos posteriormente, terminen ubicándose en la tercera categoría de las mencionadas.

\section{LAS ACCIONES CON DERECHO A VETO EN PERSPECTIVA}

Creemos que, siguiendo a Molano, modernamente puede decirse de estas acciones lo siguiente: “Con el veto, la consideración y aprobación de determinadas propuestas requiere necesariamente de la participación de ese socio, cuya presencia en las reuniones y voto favorable se hacen indispensables para que la sociedad pueda adoptar decisiones válidas y, de esta manera, el socio o accionista asegura que su intervención y opinión sean tenidas en cuenta en el proceso decisorio de la compañía”.

Visto en perspectiva, puede advertirse en el desarrollo de las acciones con derecho a veto, tres etapas en su evolución:

a) Como mecanismo de control por parte del Estado en empresas del sector privado.

b) Como mecanismo para facilitar la transferencia de empresas del Estado al sector privado.

c) Como mecanismo autónomo en el manejo de empresas privadas por parte de los particulares, es decir, sin ninguna injerencia del Estado. 
De estas tres, la última es una etapa todavía en formación, pero que no dudamos ha de expandirse, teniendo en cuenta diversos factores de la mano con el cambio de paradigmas en nuestros tiempos (así, por ejemplo, hoy por hoy, no puede hablarse sino en forma muy limitada de empresas "estratégicas").

Por otro lado, desde el punto de vista ideológico, el desarrollo de la economía de mercado ha puesto el énfasis en la promoción del interés privado, no necesariamente en oposición al sector público, sino más bien como un mecanismo más eficiente para resolver la atención de necesidades públicas a través de empresas privadas.

Otro factor a considerar es el desarrollo del propio derecho societario, que se orienta al reforzamiento de la autonomía privada.

Empero, no se trata de un proceso sencillo, pues las expectativas de un manejo autónomo del mercado o de la acción de una mano invisible, se han visto sometidos a prueba con la crisis bancaria de hace unos años, que han cuestionado el sistema existente, sin que todavía haya podido madurarse una nueva teoría económica más completa y sistemática, con una perspectiva holística y suficientemente distante.

En ese devenir, nos encontramos con un repliegue del Estado ante su incapacidad de atender las demandas sociales; viviendo los últimos estertores de lo que se llamó en Europa el "Estado de Bienestar" y que se ha ido esfumando antes de que países como el nuestro hayan podido siquiera acercarse a ello. En estos Tiempos Líquidos postmodernos, de los que nos habla Bauman con agudeza, los órganos del Estado se van desatendiendo de viejas obligaciones, recurriendo a principios de "subsidiariedad" y "externalización", para delegar funciones que antes tenía y que ahora van siendo abandonadas en favor de la iniciativa privada y del autocuidado de los propios individuos (Bauman, 2017, p. 8-9).

\section{VENTAJAS Y DESVENTAJAS DE LAS ACCIONES CON DERECHO A VETO}

\section{- Ventajas:}

a) Favorecen una mejor protección de la voluntad de las minorías.

b) Promueven una conducción más democrática y equilibrada de la sociedad.

c) Evitan situaciones de arbitrariedad por parte del accionista mayoritario.

d) Generan nuevos atractivos para formar parte de la sociedad, al brindar un beneficio adicional respecto a los comúnmente reconocidos.

e) Puede ser una variante frente al establecimiento de la unanimidad para la adopción de determinados acuerdos, haciendo innecesaria este tipo de exigencias calificadas. 


\section{- Desventajas:}

a) Aprovechamiento para la obtención de beneficios indebidos.

b) El mal uso o el uso excesivo de este tipo de acciones puede afectar la marcha dinámica y flexible de la sociedad, entorpeciendo su manejo, desde el momento en que bastaría que un accionista con esta clase de acciones se opusiera para que el acuerdo materia de veto no prospere.

c) Posibilidad de generar situaciones de parálisis corporativa.

d) Desalentar la inversión en la empresa.

\section{CONSIDERACIONES FINALES}

Creo que, como dice Flint, la LGS constituye una norma de vanguardia, lo que no impide reconocer que aún hay temas por superar, lagunas que llenar y figuras pendientes de regulación (Flint, 2010, p. 141).

En ese sentido, justamente, estimamos que sería bueno una regulación más orgánica de las llamadas acciones con derecho a veto, velando por la maximización de sus ventajas y la minimización de sus desventajas.

Estas decisiones pueden llevar consiguientemente, a que se pacte, por ejemplo, la consideración de su voto para la designación de los integrantes de ciertos órganos de gobierno, el desarrollo de nuevos productos o servicios, la emisión de ciertas acciones, etc., lo que puede darse en vía de aprobación previa o en vía de ratificación (Molano, 2011, p. 2).

Todo ello, por supuesto, teniendo siempre en cuenta que ninguno de los derechos de los accionistas puede ejercerse atentando contra los fines de la sociedad, su naturaleza o yendo contra su normal desarrollo, pues el interés personal no puede anteponerse al interés societario. ${ }^{5}$

En resumen, nos parece una alternativa interesante la posibilidad de considerar el establecimiento de este tipo de acciones en la negociación con los socios que formarán parte de una sociedad incorporándolas en el estatuto, o, también creándolas en el camino (a través de una modificación del estatuto o a través de un convenio entre accionistas). Sin embargo, hay que tener mucho cuidado al evaluar qué tipo de acuerdos podrán ser vetados, para que a la larga no se entorpezca la gestión de la sociedad en vez de favorecerla.

\footnotetext{
5 “... todos los derechos de los accionistas, cualquiera que sea la clasificación que se use, no pueden ser utilizados para obstaculizar la consecución de los fines y el funcionamiento de la sociedad, ni para interponer su interés personal e individual sobre el interés social..." (Hundskopf, 2014, p. 145).
} 


\section{REFERENCIAS BIBLIOGRÁFICAS}

Bauman, Zigmunt (2017). Tiempos Liquidos. 6ª . Edición. Barcelona: Tusquet Editores.

Brunetti, Antonio (2002). Sociedades Mercantiles. México: Editorial Jurídica Universitaria.

Bote García, María Teresa (2013). Derecho Mercantil. Madrid: Universidad a Distancia de Madrid.

Echaiz Moreno, Daniel (2009). Derecho Societario. Un nuevo enfoque jurídico de los temas societarios. Lima: Gaceta Jurídica.

Elías Laroza, Enrique (1999). Derecho societario peruano. Lima: Editora Normas Legales.

Escutti, Ignacio (2006). Sociedades. Buenos Aires: Editorial Astrea.

Flint, Pinkas. "Las acciones en la Ley General de Sociedades". En: Varios autores. A los 12 años de la Ley General de Sociedades. Lima: Grijley - Cathedra Lex.

Hundskopf Exebio, Oswaldo (2014). Derecho Comercial. Tomo XIII: Temas societarios. Lima: Universidad de Lima.

Hundskopf Exebio, Oswaldo (2012). Manual de Derecho Societario. ${ }^{\text {a }}$. Edición. Lima: Gaceta Jurídica.

Hundskopf Exebio, Oswaldo (2011). "Una clase especial de acciones: las acciones con derecho a veto". En: Ius et Praxis No. 42. Revista de la Facultad de Derecho de la Universidad de Lima. Lima.

Molano, Ricardo (2011). “El Veto: Un Mecanismo de Protección de los Minoritarios”. En: http://blogs.portafolio.co/derecho-de-los-emprendedores/el-veto-un-mecanismo-de-proteccion-de-los-minoritarios/. Consultada el 28.06.2017.

Roitman, Horacio; Aguirre, Hugo y Chiavassa, Eduardo (2010). Manual de Sociedades Comerciales. Buenos Aires: La Ley. 


\section{COMO CITAR ESTE ARTÍCULO}

CARDENAS KRENZ, Arturo Ronald. Algunas consideraciones con respecto a las acciones con derecho a veto. Revista de la Facultad de Ciencias Económicas - UNNE, Argentina. Volumen 21 Núm. 2, julio-diciembre 2018, ISSN 1668 - 6365. Págs. 15 - 23. DOI: http://dx.doi.org/10.30972/ rfce.0213725

\section{CURRICULUM VITAE}

\section{Arturo Ronald Cardenas Krenz}

Magister en Derecho Civil y Comercial. Magister en Bioética y Biojurídica. Investigador del Instituto de Investigación Científica (IDIC) y profesor de la Facultad de Derecho de la Universidad de Lima. Profesor de las Facultades de Derecho de la Universidad Femenina del Sagrado Corazón y de ESAN. Miembro Correspondiente de la Academia de Derecho y Ciencias Sociales de Córdoba. Miembro Correspondiente de la Pontificia Academia para la Vida.

Rcardena@ulima.edu.pe

Rckrenz@gmail.com 